\title{
APPLICATION OF SEMIOTICS IN ORGANIZATIONAL COMMUNICATION
}

\author{
A. Rasakumaran \\ University of Jaffna, Sri Lanka \\ rasakumaran1957@gmail.com
}

\begin{abstract}
This article presents the brand management process based on the Peircean principles of Semiotics, for sign analysis. Based on the application of semiotics for brand management, it is argued that consumers are able to receive a brand that allows the appropriation of information that leads them to build knowledge and, therefore, make purchasing decisions. Bibliographical survey and theoretical discussion were employed as the research method. Results reveal that the application of semiotics theory reduces the differences between the brand identity communicated by the organization and the brand image perceived by customers or consumers. As this study is theoretical, neither direct description of empirical object nor an experimental process being offered may be a limitation.
\end{abstract}

Keywords: Semiotics, Organizational communication, Information flows, Brand management.

\section{Introduction}

With the development of competitive markets in the last two decades, organizations have come to experience a scenario in which communication models and processes are considered essential for organizational survival (Harvel, 2006; Richmond, McCroskey \& McCroskey, 2005; Spaho, 2011). Today, with the expansion of several markets that have become part of the global context, there has also been a need for greater investments and marketing research, so that the public consumers have a clearer vision as to the quality and specificities of the products. There has been increased competition, the creation of new products and the development of technologies that increase the attributes of products and services, as well as the expansion of innovation. All this makes managers look for ways to highlight organizations, especially by highlighting their brands. 
In this sense, much research is being done about new possibilities that can raise the standards of analysis on the potential of markets and products, the development of new brands and especially the effect of these brands on the minds of the target audience. It is considered that organizational communication and its marketing and branding aspects are today responsible for sustaining the great brands in the market, because it is through the management of communication processes that information about products and services can be expressed and disseminated in society.

In the case of formal or informal flows of communication in the internal or external context of the organization, it is necessary to develop the capacity to identify, collect, filter and compile the information. This capability has been tested at all times, in order to provide support for decision making and, especially, to obtain a competitive advantage. Therefore, this requires the constant updating, with searches for new possibilities to develop strategies especially, related to creation, positioning, development and even, reestablishment of the brand.

With regard to the appropriation of information, it is argued that this is one of the main factors of the process of knowledge construction. In every consumer market, the process of building knowledge about a brand involves numerous factors. Among these factors there are psychological, biological, cultural, regional and gender aspects, which influence the construction of customer or consumer knowledge in the process of choosing products or services.

Thus, it is considered that the decision-making process for the purchase of a product or service requires knowledge, be it a priori or current, for this, individuals also need information. The appropriation of information requires sensorial factors: visual, auditory or tactile, also requiring cultural factors that, among others, are also presented by the brand image. Such representations added to the product itself make up the process of brand awareness.

In applying the Semiotics theory in the context of communication and brand knowledge, we try to interpret the possible cultural effects in the processes of signification. Thus, it is possible to reveal how the signs - here considering the brands of the organizations - can exert a communicative influence regarding the product or service in the ideas of the consumers. In the organizational context, especially in the processes of communication, marketing and branding, the Semiotics theory is relevant, since the brand whose value is one of the main assets of the organization is also a sign that emerges and is developed in the processes of communication, as a central factor in the construction of knowledge by customers or consumers. 
In this background, this study purports to analyse the communicative function of signs which influences the construction of knowledge about a particular brand by customers or consumers, which in turn influences buying decisions.

\section{Organizational communications and construction of knowledge}

Organizational communication is one of the processes that express organizational culture. It is through this the external communication flows such as those relating to the markets, can influence the business of the organization (Wrench, 2012). It is also through communication that internal communication, such as internal assets, defining action strategies and decision making flow. In order for the internal or external communication processes to be effective in creating value, favouring the positive construction of brand awareness, it is fundamental that the image of the organization be communicated to a specific public with information that is coherent with the organizational culture.

In this sense, Zornoza \& Alcamí (1999) point out that the organizational system is made possible because of the existing communication system that will allow its continuous feedback and survival. Therefore, an organization should not present to the market an image that shows little about the direction of its organizational conduct. There must be means to enable communication to enable the process of brand identification, expressing its organizational culture and, also, allowing the process of knowledge construction.

Internally, information flows reveal the structure of an organization's projects and action plans. Therefore, it is essential that such information reaches the stakeholders in a cohesive, transparent and rigorous manner so that all understand this information and that the objectives of communication are achieved. This is especially true for the brand, considering that, for an organization, the act of communicating presupposes understanding what value is for the consumer (Woodruff \& Gardial, 1996). Thus, it is necessary to know and interpret what the customer or the consumer thinks, and also to recognize their way of acting in the process of brand awareness and consumer relations. Organizational communication plays a key role in the relationships between the organization and the external public. Generally speaking, this audience is usually represented by consumers, creditors, government and society. This multiplicity of agents interested in the organization again proposes that the area of communication be prepared to present information that can be interpreted by different audiences, especially regarding the role of the brand in the external context. 
Whether it is a large productive industry or a trade, organizational information is important for management and its communication is an essentially strategic process. Therefore, it can be said that organizational communication is intertwined with formal and informal flows of information, whether internal or external.

Through the existence of informational, formal or informal flows, information permeates all the company's environments, forming part of the organizational processes in a natural way, and can exist in a registered and unregistered form. The formal flows are derived from the company's own structure, that is, routines and elements applied to the productive actions, being related to the organizational chart of the company (Jurisch, Wolf, \& Krcmar, 2010). In this case, the information recorded goes through the company's formal systems: corporate portals, Intranet networks, reports, records, documents containing standards and codes, among others. And in the unregistered form, the information circulates through meetings, courses and events formalized, but that were not explained in some type of support.

As for informal flows, they arise spontaneously, through the internal or external interpersonal relation to the organization, and are directly related to the cognitive structure of the individuals that work in the organization. It should be emphasized that informal flows are not registered in any type of support, considering that they are dialogues and non-formalized interactions among organizational subjects.

Information flows are the link between a source and a receiver, which results in the transfer of information formally or not. In relation to formal and informal flows of information in all areas of an organization, according to Chibba \& Rundquist (2004), it is possible to identify and map the formal information flows, from the recognition of three environments: the first is linked to the organizational chart itself, that is, to the interrelationships between the different units of work as directories, managements, divisions, departments, sectors, sections, etc.; the second is related to the structure of human resources, that is, the relationships between people of the different work units, and the third and last is composed by the information structure, that is, generation of data, information and knowledge through the two previous environments.

Therefore, it is possible to make energetic information flow through the knowledge and application of effective models to map, prospect, filter, treat and make available information. This provides for its rational and efficient use, directly improving the effectiveness of organizational communication. It is critical that an organization understands the importance of properly managing existing information, both in its 
internal and external environment. This facilitates the improvement of the processes that involve the organizational communication, thus being able to obtain a competitive advantage, based on this element that has a strategic character when managed efficiently.

In addition to the issues surrounding structure, process, and flows, organizational managers must be aware of the constant transformations and demands that influence their context. Elements such as rapid dissemination of information, new product development, competition, as well as crises and turbulence inherent in global markets can be considered as factors to which contemporary companies are more susceptible and can greatly influence their business. All these elements are permeated by information flows and, in turn, these are grounded in communicational processes.

In this sense, Keyton (2005) argues that it is necessary to consider that business communication requires the knowledge that this occurs in a holistic way, because it is not carried out at the margin of organizations, but is essentially associated with a particular system of management, to a specific organizational culture and that is, therefore, an expression of a concrete reality.

Therefore, it is reaffirmed that information and knowledge are crucial tools in organizational communication management processes. Importantly in a globalized scenario, these are relevant instruments for actions to strengthen the organizational image, in structuring the relationship with consumer markets, especially with respect to the brand image that may also reflect the internal environment (Petek \& Ruzzier, 2013). Consumers want to know what happens in the production environment, they want to know what the organization provides to the employees themselves and to the community around them, because they are currently more demanding and observant of the institutional image that the brand provides for those who use it and, this requires a very well-established knowledge-building process. From this perspective, strategic business communication needs to be in tune with the knowledge management proposal, which, as it is, is even more widespread than actually practiced, and definitively, to redeem the importance of internal communication, valuing diversity, which implies the plurality of ideas, experiences and opinions as fundamental attributes of the modern management process Camelia \& Laura (2008).

Petek \& Ruzzier (2013) state that constantly planning the organizational image or adjusting organizational identity to the new times, relying on knowledge management, it is possible to act in a highly competitive market through brand 
management processes, as well as staying ahead of the competition. Understanding the brand from the point of view of information management and the way it builds knowledge in the consumer's mind is to understand it more broadly than simply as the visual identity of an organization, product, or service. The American Marketing Association defines a brand as "a name, term, design, symbol, or any other feature that identifies one seller's good or service as distinct from those of other sellers. The legal term for brand is trademark. A brand may identify one item, a family of items, or all items of that seller."

In this perspective, the decision about an organizational brand, a product or a service becomes very important and, therefore, it must be thought, reflected and structured with the aid of studies and analyses that subsidize communication management strategies, based on criteria creation, sustainability and solidification of brands. Therefore, in this article some elements of Semiotics theory are highlighted, to qualify the discussion about the process of signification in the development of organizational brands.

Moore (2009) defines semiotics as "a science of signs and sign systems, and these have both physical and intellectual properties available for such scientific study". He further states that "all or our knowledge is created through semiotics, and stored as semiotic structures. A good part of our knowledge must therefore be knowledge of semiotics itself, while most of our knowledge (of semiotics, or gained through semiotics) is tacit rather than explicit". The relations between Semiotics and Communication are intimate and complementary. In this way, it is emphasized that the Semiotics theory, used in the conceptual and methodological forms, can be applied in any communication process, and some of these aspects will be approached in the next section.

\section{The management of trademarks in the communication process}

The brand is a management resource to introduce the organization to the market. It is through a brand: name, term, sign or design, that consumers identify an organization, internalizing this information that, over time, becomes part of their day to day utility. There are great examples of organizations that have established themselves in the market conquering their consumers through the brand, besides the popular acceptance of the product or service itself. It can be said that the mental brand or brand image, which is represented by the name, sign or design associated with an organization, is an intangible asset (Martin \& Kelly). But in a tangible way, positive mental associations 
with regard to brand, name, term, sign or design, result in strategic solutions that last for the life of an organization.

In short, the mental mark of an organization is an intangible asset that, in a tangible way, brings strategic solutions that last through life. Bell (2008) emphasize that when applying the different domains that brand management today calls for, a descriptive model of the brand can be conceived based on three fundamental aspects, namely: the identity, which encompasses the sign or set of signs of brand identity - as understood in the legal definition - and the marks associated with it; the object, which encompasses the different offers of the brand, as well as the organization and marketing actions that support them; and the market, which encompasses the target audiences and their different responses to the brand.

From the point of view of the target audiences of the organization, on which this study is based, it is highlighted that the role of a brand is especially to create a link with the consumer. It is considered that this link starts to identify the organization and, often, this can be more powerful determinant than the price itself, when choosing a product or service. Whether through cognitive or aesthetic, due to the colors and format of the communicated message, each consumer constructs a knowledge about the product or service and interprets a brand when viewing it, starting to consider aesthetic, symbolic and functional references in that brand, characterizing possible assigned functions.

Considering that consumers assign functions to brands, it is possible to consider that the physical image of the presentation of the brand makes a significant difference in the communication process to constitute the mental image of the brand as a result of the perception of customers. In this context, it is considered that the perception of the brand, name, or design, is the central link of organizational communication with its consumer markets even though these markets have diverse identities created by different factors, such as culture, knowledge and routines. However, consumers also communicate and comment on their impressions and thus develop the brand's public reputation.

It is therefore necessary for managers of organizations to be prepared to deal with questions about how the brand is perceived and interpreted by consumers. In this way, the goal of managing a brand image is to manage all the experiences of potential consumers, with everything that is perceived and associated with the brand, that is, the name, sign or design that represents the organization. This mainly includes the manner of presenting the brand itself, be it a name, a sign or a design. Hence the goal is to create 
ways for consumer markets to build a positive impression that can lead to organizational attitudes.

The brand image corresponds to the whole process of interaction between the brand and its public, resulting in a perception, on the basis of which will be the greater or lesser predisposition to give the brand a high value in the market. Therefore, analyzing the brand image is to study the company-public relationship, whose efficient management seems to bring countless advantages by capitalizing on brand value. And in this sense, the concept of image seems to be both a process (over time) and a product (final effect).

In this context, the information and public communication of the brand itself and all that it represents characterize instruments and processes central to the management of the image of the organization, so that it is positively linked and fixed in the mind of its consumer market. The clear association of the brand with its product or service; the way in which that brand expresses the attributes of the organization; as well as the physical and emotional benefits that the brand represents to the consumers constitute the way in which the organization is seen. Therefore, the way in which this brand is created and presented to its market is the differential of the communication processes of the organization with its stakeholders.

\section{Foundations of Peircean semiotics and market management}

In the scope of studies on organizational communication, especially in brand studies, Semiotics theory has been considered a new way of investigating problems that are part of communication management processes, such as web site management, campaign development, promotions, packaging and anything that involves the creation and support of a brand. The main objective is to deal with the varied relationships developed between these phenomena investigated and the impacts that brands cause or suffer in the market, in addition to the oscillations provoked in the target audience.

Studies on the influence of signs on individuals' actions and even on the existence of a brand are relatively recent, considering that the field of semiotic studies is ancient, having its origin in Ancient Greece (Plato and Aristotle) by the Middle Ages, until it was deepened from the 19th century, through the studies of the linguist Ferdinand Saussure and especially the scientist (physicist, chemist, philosopher and mathematician) Charles Sanders Peirce. 
The basis for the development of the semiotic analysis is the conception of the sign, object and interpretant, considering its relations present in the General Theory of Signs of Peirce. In this sense, this study has the objective of starting the discussions about the existing relations between the semiotic studies and the studies on brands, considering the elements of the organizational communication. It should be emphasized that the most different expressions existing in the brands can be considered as sign processes that, when interacting, generate interpretations or effects of meanings.

The production of sense effects based on the signs is multiple and diverse, therefore, difficult to control and even to be perceived with precision. In this context, the Semiotics theory is relevant because it is able to explain how the effects of senses are generated, and with this it is possible to design or correct paths that are better suited to different audiences, with which organizations have to communicate (Wrench, Carter\& Ward, 2015).

Importance is given to studies on the signs especially because signs are a kind of matter of language, considering that the sign represents the composition of an expression or something to be presented or exposed. The signs can be images, sounds, words, memories, flavours, etc. and are represented by language which, in turn, is responsible for the exchange of information between what a particular sign represents and who interprets it.

Peirce worked so that it was possible to make the symbolic concepts broad, general, to the point that they could serve as a basis for studies in any other science. Even though Semiotics begins to arouse the interest of other fields of knowledge, as in Communication, this is not yet an easily understandable subject, however, with a vast and rich possibility of contribution.

Although this research did not aim to deepen the theoretical contextualization about the fundamentals for the understanding of Semiotics, it was used mainly of the studies on classification systems proposed by Peirce, seeking to unite these elements with the studies on the analysis of the marks and of their expressions.

For Peirce, Semiotics is only one of the disciplines that form part of its broad philosophical structure. He states "By semiotics I mean an action, an influence, which is, or involves, a corporation of three subjects, such as a sign, its object and its interpretant, this tri-relative influence not being in anyway resolvable into actions between pairs"(Peirce cited in Umbreto, 1979) 
The scheme proposed by Peirce provides the foundations for normative sciences subdividing into Ethics, Aesthetics, Logic or Semiotics. Aesthetics is able to answer which ideals guide the feelings, the Ethics which ideals guide the conducts, and the Semiotics which the ideals that guide the thoughts, in relation to the representations of the things of the world. Considering also that in Semiotics there are three subdivisions, being the General Theory of Signs, Critical Logic and Speculative Rhetoric. The General Theory of Signs is the part of Peirceana Semiotics, which will function as a bridge, relating the Semiotics theory with the Marketing area, especially considering the studies on the marks, since this part of the Semiotics theory provides the definitions and classifications for the analysis of all types of languages, signs, signs, codes, etc. of any kind and all that they entail.

In the Peircean concept, a sign is anything that is in the place of anything to be interpreted by someone, and is therefore a relation between three elements: the sign, the object to which the sign refers and the interpretant, which is the effect that the sign creates in the mind of the recipient. The brand of an organization, in its basic function, serves first to identify it, in a second moment, to identify its products or services, and also to differentiate them from others, serving as a kind of bridge between those who produce and who uses it. However, according to Bernd (2002), the functions of brands are not only utilitarian functions, because brands function as symbolic devices, sources of sensorial, affective and cognitive associations.

Hence, by incorporating characteristics of identity and representation, the brand is a sign, considering that the brand represents an organization, a product, a service etc., these being the object and the mind of the consumer that interprets the signs, is the interpretant. According to Daniel (2007), in practice, the semiotic analysis proposes three main applications when related to the brand: the first is to analyze the sign (the brand) and define what communicative potential exists there, i.e. what effects it can, potentially generating in the consumer's mind, the second application is to define the desired interpretive effects, seeking expressiveness that can generate the effects sought, and finally, the third important application regarding the analysis of the level of similarity between two signs, with the purpose of investigate cases of suspected plagiarism.

Considering this, Ligas \& Cotte (1999) observe that the brand is a sign that carries the notion of symbolic construction and is composed of the aspects that give it expressiveness and visibility: name, logo, color, shape, slogan, etc. Already the object that the brand represents takes into account the marketing compound and all the 
complexity of the organization, its mission, vision and values, relation with the society, etc. The interpretant is the stock of mental processes generated, the interpretive effects related to the brand, which can be emotional (beauty, status, glamour, power, social acceptance, etc.), functional (comfort, performance, safety, durability, etc.) or logical (forming a habit, accepting a brand, etc.). For example, the Semiotic Triad can be viewed in the advertisement for Mercedes-Benz brand (available at https: //www.tvadmusic. co. uk/2017/03/mercedes-benz-c-class-2017/). The features of this ad can be fit into the semiotic triangle.

The symbol of Benz (a three pointed star within a circle) is used as the sign which is supported with the image of the car in front of an exquisite mansion where a young couple stand ready to get into the $\mathrm{c}$ with their pet. The three-pointed star represents its domination of the land, sea, and air. Expensive price and luxury decoration communicate success and high status. The strong colour expresses dignity and professionalism and gives the meaning of "I am speedy and young and I will surely take you there". Letters with sharp edges and angles symbolize businesslike, effective and willpower. These words together with the symbol create both functional such as security, durability, high performance and comfort and emotional interpretations such as emotional power, high status, elegance and social acceptance in the mind of the reader.

The images can be analyzed semiotically in three aspects Keane (2003), which accompany Peirce's whole triadic reasoning: the images themselves, that is: the qualisigns, sin-signs and legi-signs, the images in relation to the object they represent : icon, index, and symbol and the images in relation to the effects generated in the interpreting minds: immediate, dynamic and final. It should be said that the immediate interpretant is possibility, power. The dynamic interpretant is the effect effectively generated in the interpreting mind and is subdivided into functional, emotional and logical or habit.

Semiotics plays an important role in the analysis of the effects that a particular brand can produce through a particular receptor. As a basis for this analysis, Bairon \& Perez (2013) propose three fundamental paths: iconic qualitative aspect, singular-indicative aspect and conventional symbolic aspect. With regard to the iconic qualitative aspect, the qualitative aspects of the brand are analyzed, such as colors, lines, shapes, texture, size, sound of pronunciation, design, etc. For Rodriguez (2001), when the qualities of the brand are analyzed in detail, the abstract qualities that the visible qualities suggest can be determined, and, to a certain extent, the associations by similarity can be predicted that these qualities are able to produce. These are not precise predictions, but rather hypotheses that present some assurance that they are correct. 
Under the singular-indicative aspect, the brand is analyzed as something that exists in a context with determined space and time, thus the qualities that make up the brand colors, shape, size, matter - are seen as a function of their manipulation , use or consumption. At first, the brand is analyzed in its relation with the context to which it belongs, being examined its origins, the environment of use of the brand and what information exists about the users or consumers to whom it is destined. In a second moment, the brand is evaluated according to the functions that it performs and the purposes to which it is given (Bairon \& Perez, 2013).

With respect to the conventional-symbolic point of view, it is done in the relation between legi-sign and the object, being observed, firstly, the coherence between the expressiveness of the brand and the cultural expectations of whom the brand seeks to meet. Subsequently, the representative power of the brand is examined, or what it represents and what values fure added to it. Finally, it analyzes the type of user or consumer that the brand aims to meet and the meanings and values that the brand has for that consumer (Smith, 2016).

In this context, semiotic analysis applied to the brand is capable of providing a thorough examination of the effects of the object being analyzed as well as its effects on the mind of the person receiving the message. It is important to consider that a wellmanaged brand is capable of effectively transmitting a set of information, thereby leading consumers to experiment with it, like the brand and, in addition to repeating the act of consumption, also indicate that brand to other individuals. The mark as a sign only has a real meaning if it is appropriate to the medium to which it will be divulged and, likewise, the means of communication must be in agreement with the objectives of the message proposed by the sign, always considering the representation of the object and the interactions of the interpreter.

As far as the process of knowledge construction is concerned, two aspects are highlighted by Lencastre and Corte -Real (2010) as being interpreted and interpreted. Transposing to the brand, the interpretant is the market - from its narrowest sense to the broadest - that is the response (interpretation) that the brand has with a particular individual (interpreter), and by extension with a particular public, understood as a set of individuals or legal entities relevant to the mark by the exchange ratio they represent. (Lencastre \& Corte-Real, 2010).

It should be noted that each individual that composes target markets, for which brands are targeted, have different forms of interpretation, different perspectives and, 
especially, different forms of information appropriation for decision making. Based on the information that the brand passes, individuals construct knowledge and make purchasing decisions, defining the process of using the brand for response. This response constitutes the process of effecting the purchase, that is, action effected based on the cognitive relationship between brand and individual. In this way, the object of the brand is, in the first instance, the organization (Lencastre \& Corte-Real, 2010), since it expresses the organizational culture through communication. However, the goal of the brand is the target market, the consumer, the individuals who own or may have an interest in the product or service. Thus, it is understood that the study and use of semiotic concepts provides a more in-depth look, ranging from the conception of a brand (sign) that will represent an organization, a product or a service (object) that will be offered to a target audience (the person the company intends to target).

In this sense, the semiotic analysis, based on the General Theory of Signs of Peirce, works as a logical map, which outlines the lines of the different aspects that should lead to the analysis of any expressiveness of the brand. With this same scope, Lassar, Mittal, and Sharma (1995) affirm that the main benefit in the methodological way extracted from the Peircean Semiotics for the analysis of the mark is, at first, to open the windows of the senses and look at the sign as long as possible, their features manifest themselves. It is argued that the brand, in general, presents the possibility for consumers to express themselves and identify themselves before society in terms of values and conduct. This occurs, therefore, the marks can represent personalities, through the association with certain symbols and, consequently, leading to certain behaviors that, through the communication, are widely recognized. This kind of cycle eventually stimulates the buying process (Kevin, 1993).

This cognitive representation presented by the brand of a company implies the character demonstrated in this work, namely, that the appropriation of the existing information in a brand leads to the process of knowledge construction in an individual that, in turn, performs the process of decision-making or not. The image of a brand represents one of the most valuable assets besides being one of the main inputs used in the process of approaching the company with its consumers. However, the response of a consumer to the brand depends fundamentally on the knowledge that it possesses and, therefore, it is argued that the use of the path offered by the studies and use of semiotics is able to create brands that offer information capable of building knowledge in the consumer's mind. 


\section{Conclusion}

The brand is the expression of the identity of an organization and, therefore, plays a fundamental role in the processes of elaboration of competitive strategies, considering that these can differentiate products and services, as well as raise the potential of a certain organization. The appropriation of existing information in the brand of a company is able to build knowledge in the mind of the consumer and thereby lead to decision making. In this sense, all possible efforts to develop models and tools for brand management are valuable to the organizational environment, assisting institutions and companies.

Semiotics theory is capable of providing the conditions for unraveling languages and the way the senses are produced in relation to objects and signs. But it is a theory that has not yet been applied in the organizational context. However, even if that theory is able to provide a better understanding of markets, product design, brand development, and media positioning, the professionals involved in these tasks still do not use it often. Perhaps, these professionals consider the fact that this theory is still little disseminated and, therefore, unknown by certain professional areas.

In turn, brand management is a complex activity and has been developing over the years, considering the strong demand of organizations that aim to meet their stakeholders and gain competitive advantage. However, such management essentially depends on a set of efforts, involving the entire marketing team and the other members of the organization as a whole. In this sense, it is fundamental to understand the relations between the transmission of information of a brand and the way the receiver perceives and interacts with it.

The purpose of this study was to relate, although initially and succinctly, the process of brand management with the principles of the Semiotics theory, highlighting the Peirce model for the analysis of signs. Thus, it was possible to bring out that the application of Semiotics theory is able to reduce the deficiencies in the interpretation of information about the organization's brand identity and the image perceived by consumers in the organization's public communication processes. Such processes can be understood as fields of construction of public knowledge about a particular brand. In this way, it is possible to affirm that the application of the Semiotics theory can be considered as an effective resource in the trademark management process. 


\section{References}

Bairon, S. \& Perez, C. (2013). The meta-discourse of contemporary brands and the indexing of consumption: a way to build bonds of meaning. SocialSemantics, 23(4). https://doi.org/10.1080/10350330.2013.799011

Bell, S. (2008). International brand management of Chinese companies. PhysicaVerlag: Heidelberg.

Bernd, S. (2002). Marketing Experimental. São Paulo: Nobel. Camelia, S \& Laura, P. (2008). Managerial Communication. Available at: https://mpra.ub.unimuenchen.de/7104/1/MPRA_paper_7104.pdf

Chibba, A. \& Rundquist, R. (2004). Mapping flows - An analysis of the information flows within the integrated supply chain. Proceedings of the 16th Annual Conference for Nordic Researchers in Logistics. Available at: http://www.divaportal.org/smash/get/diva2:237919/fulltext01

Daniel, C. (2007). Semiotics- The Basics. Routledge Taylor and Francis Group. London and New York.

Harvel, L. A. (2006). Effective communication: A comparison of tools for organizations. The Review of Communication, 6(1\&2), 141-143.

Jurisch, M., Wolf, P. \& Krcmar, H. (2010). Toward a Formal Approach to Process Bundling in Public Administrations. In Wimmer, M. A., Chappelet, J.L., Jassen, M., \& Scholl, H. J. (eds.) Electric Government. EGOV 2010. Lecture Notes in Computer Science, vol. 6228. Springer, Berlin, Heidleberg.

Keane, W. (2003). Semiotics and the social analysis of material things. Language \& Communication, 23, 409-425.

Kevin, K. L. (1993). Conceptualizing, measuring and managing customer-based brand equity. Journal of marketing, Chicago, 57(5), 1-22.

Keyton, J. (2005). Communication and Organizational Culture: A Key to Understanding Work Experiences. Sage Publications Inc.: United Kingdom.

Lassar, W., Mittal, B. \& Sharma, A. (1995). Measuring customer-based brand equity. Journal of Consumer Marketing, 12 (4), 11-19. Available at: https://doi.org/10.1108/07363769510095270 
Lencastre, P. \& Côrte-Real, A. (2010). A Brand Triangle Model to Avoid Branding Myopia (May 21, 2010). The IUP Journal of Brand Management, 7 (1\&2), 7691. Available at: https://ssrn.com/abstract $=1612676$

Ligas, M. \& Cotte, J. (1999). The process of negotiating brand meaning: a symbolic interactionist perspective. Advances in Consumer Research, 26, 609-614.

Martin, N \& Kelly, M. (nd) Intangible Assets. Available at: http://www.cpaireland.ie/ docs/ default-source/ Students/ Study-Support/P1-Corporate-Reporting/ intangible-assets.pdffisfvrsn $=0$

Moore, R. (2009). Semiotics: The Key. Smashwords Edition. Available at: https://www.amazon.de/Semiotics-Key-English-Ralph-Moore-ebook/dp/ B002KE42QW

Pallavi Swain, P., Sharma, S. \& Choudhari, V. (nd). Formal and Informal Communication In Business Organizations. Available at: http://tmimtjournal.org/Pdf/Poceddings/Track1/Track1_Paper9.pdf

Petek, N. \& Ruzzier, M. K. (2013). Brand Identity Development and the Role of Marketing Communications: Brand Experts' View. Managing Global Transitions, 11 (1), 61-78.

Petrilli , S. (2009). Signifying and Understanding: Reading the Works of Victoria Welby and the Signific Movement. De Gruyter Mouton, Berlin.

Richmond, V.P., McCroskey, J. C. \& McCroskey, L.L. (2005). Organizational Communication for Survival (3rd ed.) New York: Pearson Education, Inc.

Smith, K. (2016). How to Conduct Customer Analysis and Customer Segmentation. Available at: https://www.brandwatch.com/blog/how-to-write-customeranalysis/

Spaho, K. (2011).Organizational communication as an important factor of company success: case study of Bosnia And Herzegovina. Business Intelligence Journal, 4(2), 9-17.

Umbreto, E. (1979). A Theory of Semiotics. Indiana University Press, Bloomington.

Woodruf, F, R., B. \& Gardial, S. F. (1996). Know your customer: new approaches to understanding customer value and Satisfaction. Malden: Blackwell Business. 1996. 
Wrench, J. S. (2012). An Introduction to Organizational Communication. Available at: https://2012books.lardbucket.org/pdfs/an-introduction-to-organizationalcommunication.pdf

Wrench, J.S., Punyanunt-Carter, N. \& Ward, M. Sr. (2015). Organizational communication: theory, research, and practice. Flat World Knowledge, Inc., Washington, D.C.

Zornoza, C. C \& Alcamí, R. L. (1999). The Enabling Role of Information Technologies on the Emergence of New Organizational Forms.M@n@gement, 2(3), 251-261. Available at: http://www.management-aims.com / download.phpfiid $=8 \& 1=$ en $\& \mathrm{f}=23$ Camison.pdf 